\title{
Berechnung der Steuerschuld
}

Die Berechnung der Steuerschuld erfolgt, sofern der Leistungsempfänger Steuerschuldner ist, auf der Basis des Nettobetrages in der Rechnung oder Gutschrift (= Rechnung erstellt durch Leistungsempfänger), wie Abschnitt 13b.13. (1) S. 1 UStAE zu entnehmen ist.

Für die Berechnung der Steuer für Umsätze, die unter das Grunderwerbsteuergesetz fallen, ist Abschnitt 10.1 (7) S. 6 und 7 UStAE zu beachten. Hier heißt es:

(7)[...]6Bei einer Grundstücksveräußerung gehört die gesamtschuldnerisch von Erwerber und Veräußerer geschuldete Grunderwerbsteuer auch dann nicht zum Entgelt für die Grundstücksveräußerung, wenn die Parteien des Grundstückskaufvertrags vereinbaren, dass der Erwerber die Grunderwerbsteuer allein zu tragen hat, weil der Erwerber mit der Zahlung der vertraglich übernommenen Grunderwerbsteuer eine ausschließlich eigene Verbindlichkeit begleicht. 7Gleiches gilt hinsichtlich der vom Käufer zu tragenden Kosten der Beurkundung des Kaufvertrags und der Auflassung, der Eintragung ins Grundbuch und der zu der Eintragung erforderlichen Erklärungen.[...][27]

Nach Abschnitt 13b.13. (4) S. 1 UStAE ist der jeweils gültige Steuersatz im Sinne des $\S 12$ UStG auf die Bemessungsgrundlage anzuwenden.

Für den Fall der Änderung der Bemessungsgrundlage ist eine Korrektur gemäß § 17 UStG erforderlich (Abschnitt 13b.13. (4) S. 3 UStAE). 